\title{
RANCANG BANGUN APLIKASI SMART SCHOOL PADA PENGENDALI PERALATAN ELEKTRONIK MENGGUNAKAN PLC
}

\author{
Oleh : Sri Kusumastuti \\ Staf Pengajar Teknik Elektro Politeknik Negeri Semarang \\ J1.Prof. H. Sudarto SH, Tembalang, Semarang 50275 \\ E-mail : kuzumastuti@gmail.com
}

\begin{abstract}
Abstrak
Guru dan murid dapat melaksanakan proses belajar hingga mendapatkan prestasi yang maksimal di sekolah jika sekolah menerapkan disiplin yang baik, memberi rasa nyaman dan aman. Disiplin waktu belajar bergantung pada bel sekolah, rasa nyaman siswa sangat didukung sarana di kelas, keamanan sekolah terjaga jika bebas dari pencurian. Kontrol bel sekolah, kipas angin, lampu penerangan dan sistem keamanan di sekolah selama ini masih dilakukan secara konvesional. Cara ini sangat memungkinkan terjadinya human error. Penelitian ini akan dibuat sistem kontrol beberapa peralatan elektronik sekolah berbasis PLC. Peralatan yang dikontrol adalah : (1) Bel sekolah yang berkerja secara otomatis untuk jadwal harian maupun jadwal ujian, (2) Lampu di kelas bekerja secara otomatis secara otomatis pada jam sekolah jika cahaya ruang kelas kurang terang, (3) Kipas angin kelas bekerja otomatis selama jam sekolah saat suhu > $27^{\circ} \mathrm{C}$, (4) Lampu gedung di luar kelas menyala secara otomatis mulai pukul 17.30 hingga pukul 05.00 WIB, (5) Lampu kamar mandi menyala secara otomatis saat kamar mandi digunakan, (6) Alarm pengaman bekerja jika ada pencuri masuk ke dalam lab. komputer.
\end{abstract}

Kata kunci: Kontrol elektronik, PLC. remote $R F$

\section{Pendahuluan}

Sekolah yang disiplin, nyaman dan aman sangatlah penting, agar siswa di sekolah dapat mencapai prestasi yang terbaik dan guru dapat menampilkan kinerja dengan maksimal. Salah satu piranti yang mempunyai peranan penting untuk menciptakan kedisiplinan di sekolah adalah bel sekolah. Dengan bel sekolah, seorang guru dapat mengetahui kapan harus mulai mengajar, kapan istirahat dan kapan harus selesai mengajar sehingga proses belajar mengajar dapat berjalan tepat waktu.

Bel sekolah terbagi menjadi dua jenis yaitu bel sekolah secara konvensional/manual dan secara elektrik. Kedua cara tersebut masih tergantung pada peranan manusia sebagai pelaksana sistem. Tidak dapat dipungkiri bel sekolah yang tergantung oleh peranan manusia memungkinkan terjadinya human error seperti adanya keterlambatan membunyikan, sehingga akan berpengaruh pada jalannya jam pelajaran selanjutnya.
Berbagai upaya dilakukan sekolah untuk menciptakan kenyamanan disamping kedisiplinan. Kelas yang nyaman membantu mempermudah siswa dalam menyerap pelajaran. upaya yang dilakukan diantaranya, memasang kipas angin dan memasang lampu penerangan di kelas. Kipas angin dipasang agar siswa tidak kepanasan saat udara panas dan lampu dipasang untuk penerangan saat cahaya di kelas kurang terang. Di sekolah lampu penerangan tidak hanya dipasang didalam kelas, lampu penerangan juga dipasang di luar kelas dan di dalam kamar mandi. Dalam pemakaian peralatan elektronik ini, hal yang sering terjadi adalah pengguna lupa mematikan usai peralatan tersebut digunakan. Hal ini mengakibatkan pemborosan daya listrik.

Disamping tersedianya peralatan pendukung, kenyamanan dapat tercipta jika keamanan sekolah terjamin. Penjaga sekolah mempunyai peran penting dalam menjaga keamanan sekolah. Keterbatasan jumlah 
penjaga, menyebabkan beban waktu kerjanya menjadi panjang sehingga mudah kelelahan. Penjaga sekolah yang kelelahan akan mudah ketiduran yang berdampak mudah kecurian. Untuk membantu menciptakan kedisiplinan, kenyamaan dan keamanan sekolah, penelitian ini merancang dan membuat aplikasi smart school untuk kontrol peralatan elektronik di sekolah.

\section{Desain Alat}

\subsection{Blok Diagram}

Blok diagram Aplikasi Smart School Pada Pengendali Peralatan Elektronik terlihat pada gambar 1.

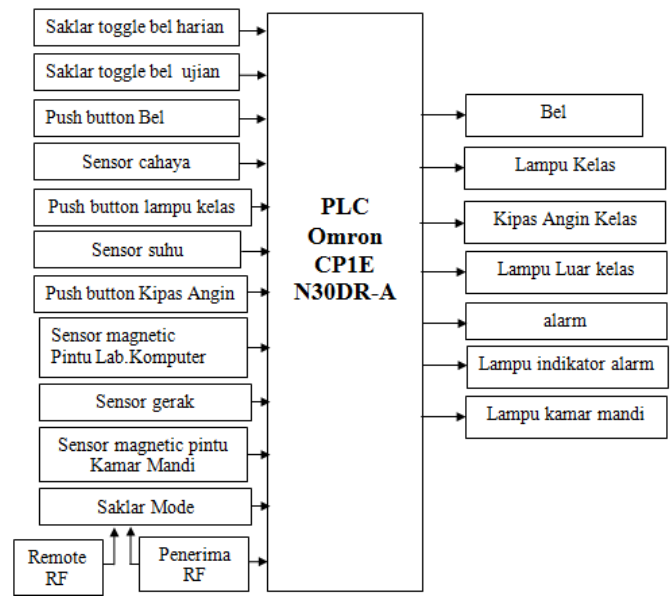

Gambar 1. Blok Diagram Alat

\subsection{Deskripsi Kerja}

Aplikasi Smart School Pada Pengendali Peralatan Elektronik adalah sistem yang digunakan untuk mengontrol bel sekolah, lampu kelas, kipas angin kelas, lampu penerangan luar kelas, lampu kamar mandi dan alarm pengaman lab.komputer dengan menggunakan PLC.

Bel sekolah dapat bekerja otomatis untuk 2 jadwal yaitu, (1) jadwal harian, dan (2) jadwal ujian. Untuk memilih jadwal yang dikehendaki, disediakan 2 saklar toggle : saklar toggle untuk jadwal harian dan saklar toggle untuk jadwal ujian. Pengguna tinggal mengaktifkan salah satu saklar toggle untuk menentukan jadwal yang dipilih. Disediakan juga tombol bel manual untuk keperluan kondisi tertentu.

Lampu ruang kelas pada jam sekolah menyala secara otomatis ketika sensor cahaya mendeteksi cahaya kelas kurang terang. Untuk memenuhi keperluan kondisi tertentu disediakan saklar push button untuk menyalakan dan mematikan lampu kelas secara manual.

Kipas angin ruang kelas pada jam sekolah, menyala secara otomatis ketika sensor suhu mendeteksi suhu $>27^{\circ} \mathrm{C}$. Untuk memenuhi keperluan kondisi tertentu disediakan saklar push button untuk menyalakan dan mematikan kipas angin secara manual.

Lampu Penerangan di luar kelas menyala secara otomatis pada jam 17.30 WIB dan mati pada jam 05.00 WIB.

Lampu kamar mandi menyala otomatis ketika pintu kamar mandi ditutup/kamar mandi sedang digunakan. Saklar magnetic dipasang di daun pintu dan di pintu. Ketika pintu ditutup maka kontak saklar magnetic akan tertutup (on), inputan ini digunakan untuk menyalakan lampu.

Pada lab.komputer dipasang alarm dan lampu indikator pengaman yang bekerja diluar jam sekolah. Untuk mendeteksi pintu dibuka pencuri dipasang saklar magnetik pada pintu dan daun pintu lab.komputer. Sedangkan pergerakan pencuri dideteksi dengan menggunakan sensor gerak. Alarm dan lampu akan bekerja jika pencuri membuka pintu(kontak saklar magnetic off) atau ketika sensor mendeteksi pergerakan pencuri di dalam lab. Komputer. Alarm dan lampu bekerja nyala 2 detik mati 2 detik secara berulang dan bergantian. Ketika pencuri berusaha untuk mematikan alarm dengan cara menutup kembali pintu, alarm tidak dapat mati. Alarm hanya bisa dimatikan oleh penjaga sekolah dengan menggunakan remote $\mathrm{RF}$.

\section{Hasil dan Pembahasan 3.1 Modul Sensor suhu}


Sensor suhu yang digunakan adalah thermocouple. Modul ini dilengkapi dengan seven segment serta tombol up down start dan stop. Seven segment digunakan untuk menampilakan suhu batas bawah, suhu terukur dan suhu batas atas. Sedangkan tombol up down digunakan sebagai setting besaran suhu. Tombol up down bagian start digunakan untuk setting besaran suhu batas bawah dan tombol up down bagian stop digunakan untuk setting besaran suhu batas atas. Keluaran modul sensor suhu berupa kontak. Kontak ini digunakan sebagai inputan PLC untuk menggerakkan kipas angin di ruang kelas, jika besaran suhu sesuai dengan setting yang dilakukan.

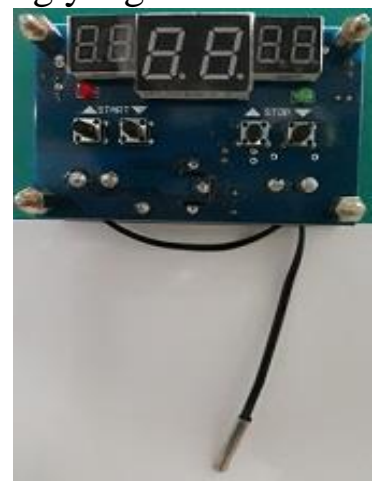

Gambar 2. Skema sensor suhu

Tabel 1. Modul Sensor Suhu

\begin{tabular}{|c|c|c|c|}
\hline No & $\begin{array}{l}\text { Suhu } \\
\text { Terukur } \\
\quad\left({ }^{\circ} \mathrm{C}\right)\end{array}$ & $\begin{array}{l}\text { Kontak } \\
\text { Output }\end{array}$ & Keterangan \\
\hline 1. & 25 & Terbuka & \multirow{5}{*}{$\begin{array}{l}\text { Start }: 25 \\
{ }^{\circ} \mathrm{C} \\
\text { Stop }: 27 \\
{ }^{\circ} \mathrm{C}\end{array}$} \\
\hline 2. & 26 & Terbuka & \\
\hline 3. & 27 & Tertutup & \\
\hline 4. & 26 & Tertutup & \\
\hline 5. & 25 & Terbuka & \\
\hline
\end{tabular}

\subsection{Modul Sensor cahaya}

Modul sensor cahaya terdiri dari sensor cahaya LDR dan rangkain pengkondisi sinyal dengan output modul berupa tegangan 220 Vac. Keluaran modul dihubungkan dengan coil relay 220 Vac, kontak relay sebagai inputan PLC.

Tabel 2. Modul Sensor cahaya

\begin{tabular}{|l|l|l|}
\hline No & $\begin{array}{l}\text { Kondisi } \\
\text { Cahaya }\end{array}$ & \multicolumn{1}{|c|}{$\begin{array}{c}\text { Output } \\
\text { modul sensor } \\
\text { cahaya }\end{array}$} \\
\hline 1. & Terang & $0 \mathrm{~V}$ \\
\hline 2. & Gelap & $220 \mathrm{Vac}$ \\
\hline
\end{tabular}

Ketika gelap, output modul sensor cahaya bertegangan $220 \mathrm{Vac}$ dan input PLC logic ' 1 ' . Inputan ini digunakan untuk menghidupkan lampu kelas. Ketika terang, output modul sensor cahaya 0 Vac dan input PLC logic '0' dan lampu kelas mati.

\subsection{Sensor magnetic}

Sensor magnetic merupakan saklar yang bekerja berdasarkan prinsip kemagnetan. Magnet berfungsi sebagai penarik dan sebagai pelepas kontak-kontaknya. Sensor magnetic ditunjukkan pada gambar berikut.

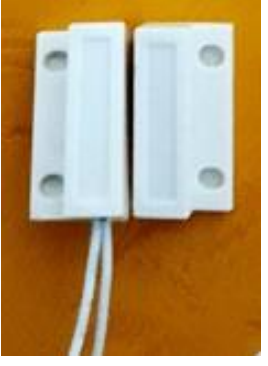

\section{Gambar 3. Sensor magnetic}

Sensor magnetic terdiri dari dua bagian yang terpisah, pada penelitian ini bagian yang pertama dipasang pada daun pintu dan bagian yang ke-2 dipasang pada pintu, keduanya dipasang berhadapan.

Tabel 3. Sensor Magnetic Pintu

\begin{tabular}{|c|c|c|}
\hline No. & Kondisi & $\begin{array}{c}\text { Kontak } \\
\text { Sensor magnetic }\end{array}$ \\
\hline 1. & Pintu terbuka & Terbuka \\
\hline 2. & Pintu tertutup & Tertutup \\
\hline
\end{tabular}

Pada saat pintu lab. komputer tertutup kemudian dibuka pencuri, terjadi perubahan kondisi kontak sensor magnetic dari tertutup menjadi terbuka. Kondisi tersebut digunakan sebagai inputan PLC untuk menyalakan alarm.

Saklar magnetic juga digunakan di pintu kamar mandi. Kondisi pintu terbuka, kontak saklar magnetic terbuka, pada kondisi 
tersebut lampu kamar mandi akan mati. Ketika pintu kamar mandi tertutup (sedang digunakan), kontak saklar magnetic menjadi tertutup, lampu kamar mandi akan menyala.

\subsection{Modul Sensor Gerak}

Modul Sensor gerak menggunakan sensor PIR dengan output berupa tegangan 220 Vac. Ketika terdapat gerakan dalam jangkauan sensor maka output modul akan mengeluarkan tegangan sebesar 220 Vac. Tegangan ini dihubungkan dengan coil relay 220 Vac, kontak relay digunakan sbg inputan PLC. Ketika ada gerakan pencuri di Lab.Komputer diluar jam sekolah, terjadi perubahan kondisi input dari kontak terbuka menjadi tertutup. Kondisi perubahan ini digunakan PLC untuk menggerakkan Alarm.

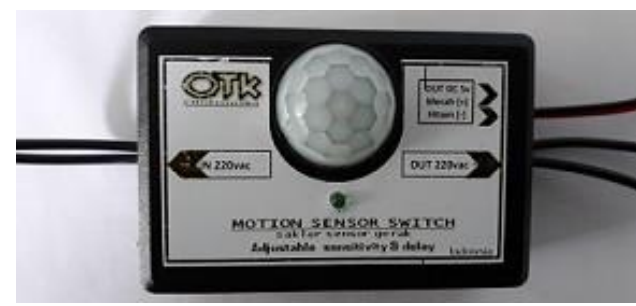

Gambar 4. Modul Sensor Gerak

Tabel 4. Jarak Jangkauan Deteksi Sensor Gerak

\begin{tabular}{|c|c|c|}
\hline No. & $\begin{array}{c}\text { Jarak Gerakan } \\
\text { dengan sensor } \\
(\mathrm{cm})\end{array}$ & $\begin{array}{c}\text { Out Modul } \\
\text { Sensor Gerak }\end{array}$ \\
\hline 1. & 100 & $220 \mathrm{Vac}$ \\
\hline 2. & 200 & $220 \mathrm{Vac}$ \\
\hline 3. & 300 & $220 \mathrm{Vac}$ \\
\hline 4. & 400 & $220 \mathrm{Vac}$ \\
\hline 5. & 500 & $220 \mathrm{Vac}$ \\
\hline 6. & 600 & $220 \mathrm{Vac}$ \\
\hline 7. & 700 & $220 \mathrm{Vac}$ \\
\hline 8. & 800 & $220 \mathrm{Vac}$ \\
\hline 9. & 900 & $220 \mathrm{Vac}$ \\
\hline 10. & 990 & 0 \\
\hline
\end{tabular}

\subsection{Pemancar dan Penerima RF}

Pemancar RF bekerja pada frekuensi 315 $\mathrm{MHz}$ dengan jarak jangkauan $10 \mathrm{~m}$. Output penerima RF berupa kontak. Kontak output penerima RF digunakan sebagai inputan PLC. Ketika tombol remote RF ditekan, kontak output penerima RF tertutup, ketika dilepas kontak menjadi terbuka.

Pada penelitian ini pemancar penerima RF dipergunakan di Lab. Komputer, difungsikan untuk mengontrol sistem alarm. Pada saat jam sekolah sistem alarm dinonaktifkan dan ketika diluar jam sekolah, sistem alarm diaktifkan. Pada saat sistem alarm sedang aktif kemudian pintu dibuka atau ada gerakan didalam Lab.Komputer maka alarm akan berbunyi. Bunyi alarm hanya bisa dimatikan oleh penjaga dengan menggunakan remote RF atau saklar mode.

Tabel 5. Pemancar dan Penerima RF

\begin{tabular}{|l|l|l|l|}
\hline No. & $\begin{array}{l}\text { Tombol } \\
\text { Remote } \\
\text { Pemancar } \\
\text { RF }\end{array}$ & $\begin{array}{l}\text { Kontak } \\
\text { Output } \\
\text { Penerima } \\
\text { RF }\end{array}$ & Sistem alarm \\
\hline 1 & Ditekan & Tertutup & Aktif \\
\hline 2 & Dilepas & Terbuka & Aktif \\
\hline 3 & Ditekan & Tertutup & Tidak Aktif \\
\hline 4 & Dilepas & Tertutup & Tidak Aktif \\
\hline 5 & Ditekan & Tertutup & Aktif \\
\hline 6 & Dilepas & Terbuka & Aktif \\
\hline 7 & Ditekan & Tertutup & Tidak Aktif \\
\hline 8 & Dilepas & Tertutup & Tidak Aktif \\
\hline
\end{tabular}

\subsection{Peralatan Kontrol Penjaga Sekolah}

Di ruang penjaga sekolah terdapat peralatan elektronik untuk mengontrol sistem.

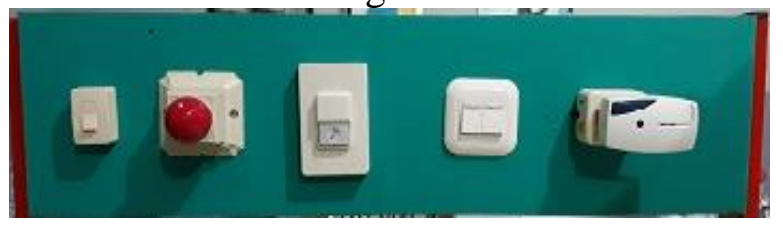

Gambar 5. Modul Peralatan Kontrol

Penjaga Sekolah

Pada ruang penjaga sekolah terdapat saklar mode, lampu indicator alarm, push button bel manual, saklar toggle bel harian, saklar toggle bel harian dan buzer alarm pencurian. 
Tabel 6. Fungsi peralatan Kontrol Penjaga Sekolah

\begin{tabular}{|l|l|}
\hline \multicolumn{1}{|c|}{ Peralatan } & \multicolumn{1}{|c|}{ Fungsi } \\
\hline Saklar mode & $\begin{array}{l}\text { Mengendalikan } \\
\text { mode otomatis }\end{array}$ \\
\hline $\begin{array}{l}\text { Lampu indicator } \\
\text { Alarm }\end{array}$ & $\begin{array}{l}\text { Lampu indikasi } \\
\text { alarm pencurian } \\
\text { berbunyi }\end{array}$ \\
\hline $\begin{array}{l}\text { Push button bel } \\
\text { manual }\end{array}$ & $\begin{array}{l}\text { Mengaktifkan bel } \\
\text { secara manual }\end{array}$ \\
\hline $\begin{array}{l}\text { Saklar toggle bel } \\
\text { harian }\end{array}$ & $\begin{array}{l}\text { Mengaktifkan Bel } \\
\text { secara otomatis } \\
\text { sesuai jadwal harian }\end{array}$ \\
\hline $\begin{array}{l}\text { Saklar toggle bel } \\
\text { ujian }\end{array}$ & $\begin{array}{l}\text { Mengaktifkan Bel } \\
\text { secara otomatis } \\
\text { sesuai jadwal ujian }\end{array}$ \\
\hline Buzer & Alarm pencurian \\
\hline
\end{tabular}

\section{Kesimpulan}

Rancang bangun aplikasi smart school pada pengendali peralatan elektronik menggunakan PLC Omron CP1E- N30DRA dapat berfungsi untuk :

1. Mengontrol bel sekolah dengan dua pilihan jadwal, jadwal harian dan jadwal ujian.

2. Mengontrol kipas angin kelas bekerja pada jam sekolah pada saat suhu ruang kelas $>27^{\circ} \mathrm{C}$ dan akan mati pada suhu < $25^{\circ} \mathrm{C}$.

3. Mengontrol lampu kelas, menyala pada jam sekolah ketika cahaya yang masuk ruang kurang.

4. Mengontrol lampu luar kelas, menyala secara otomatis mulai pukul 17.30 hingga pukul 05.00 WIB.

5. Mengontrol Lampu kamar mandi, menyala ketika kamar mandi digunakan (pintu ditutup).

6. Membunyikan alarm dan menyalakan lampu indikator alarm ketika pintu lab.komputer dibuka atau terdapat pergerakan di dalam lab.komputer diluar jam sekolah. Alarm hanya bisa dimatikan dengan remote $\mathrm{RF}$ oleh penjaga sekolah.

7. Bel sekolah, kipas angin dan lampu kelas dapat dikontrol secara manual dengan tombol push button.

\section{DAFTAR PUSTAKA}

Heri Sudarmanto. 2009.Otomatisasi Bel Sekolah sebagai Media Penerapan Kedisiplinan.Jurusan Teknik Elektro, Fakultas Teknik, Universitas Negeri Semarang.

Muhammad Sabri Annas dan Satria Gunawan Zain. 2014. Prototype Bel Sekolah Otomatis Berbasis Mikrokontroler Atmega32. Fakultas Teknik, Universitas Negeri Makassar.

Raka Agug dkk.2011.Rancang Bangun Bel Sekolah Otomatis Berbasis Mikrokontroler AVR ATMEGA8, Jurusan Teknik Elektro, Fakultas Teknik, Universitas Udayana : Bali. 